Burns as reading "If a body catch a body, coming through the rye", he says he'd like to be a catcher in the rye, the only tall person to catch the thousands of little kids playing in the field of rye and saving them from running off the cliff at the edge of the field. He knows it's crazy, but that's what he'd like to be.

Sydney Brenner is at the Molecular Sciences Institute, Berkeley, California 94704, USA.

\section{Mozart, McCartney and sexual selection}

\section{The Mating Mind: How Sexual Choice Shaped the \\ Evolution of Human Nature \\ by Geoffrey Miller \\ Heinemann/Doubleday: 2000. 528 pp.

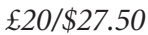

\section{Margaret A. Boden}

This book is an exhilarating example of joined-up thinking - not to mention elegantly joined-up writing. Indeed, it's so joined-up that no one reviewer could do it justice. It ranges from the origins of Homo sapiens, through the details of human sexual anatomy, to the ubiquity of humour, the glories of Mozart and the romance of "flowers that fade, candles that burn, overpriced dinners, and walks on exotic beaches". And it seeks to explain all these things in evolutionary terms.

But how? As Geoffrey Miller remarks, romantic presents don't increase a woman's survival prospects as much as they reduce a man's bank account. Why does a man bother? And why is a woman amenable in the first place? As for Mozart, how could evolution account for the hard work even he had to put into his composing, or for the international music industry that rests on Mozart - and the Beatles?

And what explains other cultural and aesthetic products - science, dance, craftwork, politics, religion ... ? One might say that these things feature in human cultures because they bring pleasure, of one sort or another. But pleasure, Miller repeatedly insists, is what evolutionary theory must explain.

It does this primarily by way of Darwin's second evolutionary principle: not natural selection, but sexual selection. Despite obvious examples such as the peacock's tail, says Miller, modern biologists and evolutionary psychologists - not to mention laymen commonly ignore this principle when they apply evolutionary thinking to psychological and cultural phenomena. He discusses countless cases of anatomical, psychological and cultural features whose explanation involves sexual selection.

That explanatory reference, however, may be highly indirect. Miller is nothing if not subtle. He's well aware that a detailed evolutionary explanation of Mozart's 40th or McCartney's Yesterday is no more likely than an explanation of why this hummingbird's tail is green and ten centimetres long, whereas that one's is red and much shorter. Indeed, it's even less likely. We can, perhaps, hope to find out just which genes, and which developmental conditions, influence the colour and length of hummingbirds' tails, and which biochemical mechanisms are involved. But to explain how Mozart wrote his 40th, or why Yesterday is now considered a classic, would require several even more difficult achievements.

We would need a clear statement of the aesthetic principles involved, and an evolutionary explanation of why those features give us pleasure. We'd need a detailed culturalhistorical understanding of the musical styles of the times.

We would need knowledge of Mozart and McCartney as individual artists, with their own personal 'signatures', and of any chance psychological associations involved. Not least, we'd need an understanding of how human creativity is motivated, how it functions at the cognitive level, and why it evolved in the first place. Don't hold your breath.

But that's not to say that none of these questions can be fruitfully approached from an evolutionary viewpoint. Miller has much to say about the origins of creativity in general, and also of some particular aesthetic principles. He regards human creativity as an example of "protean" (unpredictable) behaviour. Unpredictability has co-evolved in predator-prey behaviour, for instance. But that is explicable by Darwin's first principle: natural selection. How can protean behaviour - and protean thinking-befavoured by sexual selection?

To cut Miller's long, and carefully argued, story short, increased brain-size and behavioural flexibility formed a positive-feedback loop, because of runaway sexual selection. Within limits, surprise is not only attentiongetting but motivating - which is to say, pleasurable. To be surprised, and to be bored, implies a capacity for recognition, or even prediction. In short, both surprise and boredom require brain cells.

Similarly, the anticipation and preemption of boredom require brain cells. The more complex the expected patterns, and the more subtle the surprises, the more brainpower is required to generate and appreciate them. So the females' attention is captured by the more surprising males, but the females themselves need intelligence to be surprised in the first place. And the males, naturally (sic), appreciate being appreciated: a female too dim to recognize one's adventurousness is not a good prospect for mating. So malefemale co-evolution ratchets up the size of the cerebral cortex until the anatomy of the birth

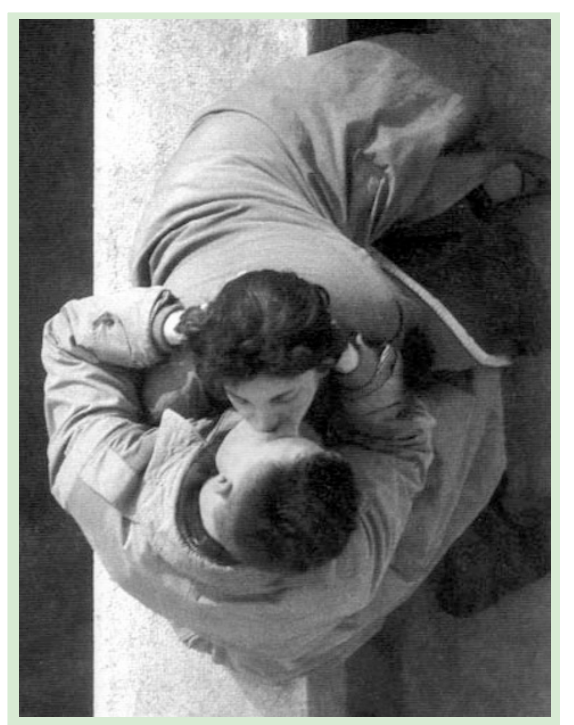

\section{Vistas of love}

Love \& Desire: Photoworks by William A. Ewing (Thames \& Hudson/Chronicle Books, $\mathfrak{E} 16.95 / \$ 35)$ is a collection of photographs showing love, affection and desire in their myriad forms.

canal calls a halt. In short, the large brains and complex intelligence of Homo sapiens aren't due to natural selection (how many brain cells do you need to pick a berry, or catch a buffalo?), they're due rather to sexual selection - but they come in handy later for survival purposes.

Cultural activities such as craft, music, decoration and dance provide not only pleasurable surprises (remember Robert Herrick's poem, "A sweet disorder in the dress ..."?), but also fitness indicators. These may be more or less direct. Someone who can join in energetic and precisely patterned dancing for hours clearly has physical strength and accomplished body control, and may be an acceptable mate. (Compare the male peacock, strong enough to grow and carry that cumbersome tail.)

Or consider symmetry. It's well known that facial and bodily symmetry contribute to judgements of sexual attractiveness or physical beauty. Miller suggests that the appreciation of symmetry in cultural artefacts (not only pottery and jewellery, but ritual practices and mathematics) utilizes the same cognitive mechanisms, and has similarly positive motivating effects. Bodily symmetry is preferred because it is an indicator of biological fitness: symmetry is hard for the genes to achieve. And it's hard for human craftsmen to achieve, too. Someone capable of the physical effort and self-control needed to make a perfectly symmetrical flint axe-head is fitter (in the Darwinian sense) than someone who is not, and a better prospect for mating. As Miller points out, a high proportion of superbly crafted prehistoric axe-heads are 
not only beautifully polished, sharp and symmetrical, but - as electron microscopy shows - were never actually used. So why were they made? His answer is that they were valued, as we say, for their own sake - in other words, for their ability to give us pleasure, which in turn rests on their value as fitness indicators of the men who made them.

Miller has many stimulating and unexpected things to say about these, and other, cultural matters. He's also good at jokes. His book will excite many people, and infuriate others - especially if they don't read it carefully. The Mating Mind is as far from naive biological determinism as it could be, without losing sight of our evolutionary heritage altogether. Reading this book enables a rich confusion of apparently unrelated details to fall into place - and isn't that what science is all about?

Margaret A. Boden is in the School of Cognitive and Computing Sciences, University of Sussex, Falmer, Brighton BN1 9QN, UK.

\section{Statistical detective}

\section{Statistics on the Table: The \\ History of Statistical \\ Concepts and Methods \\ by Stephen M. Stigler \\ Harvard University Press: 1999. 448 pp. \\ \$27.95, \$45}

\section{lan Hacking}

Stephen Stigler's previous book The History of Statistics: The Measurement of Uncertainty before 1900was a rare but splendid example of the history of a science written by one of its practitioners. It also conveyed a wry wit and insatiable curiosity that were not, however, allowed to distract from the main story. Stigler has also written occasional articles over the years, expressing his detective's delight in uncovering obscure but charming facts. In Statistics on the Table he has revised these pieces, which, although organized to develop a number of systematic lines of thought, are often so interesting individually that this could serve as a bedside book.

The title comes from a private letter by Karl Pearson, who wrote that, since you can draw any number of conclusions - sound and unsound - from statistical data, you should always put your data on the table and show how you analyse them before you state your inferences. Stigler shows how the desire to present data in compact, unbiased and accessible ways motivated the founding figures of his discipline. He also applies the motto to himself, setting out the data that bear on his own historical problems and telling how he came by them.

His focus is on figures who now seem minor; some you would never encounter

without Stigler as guide. Even when he turns to the famous, he directs us to the margins of their careers. Yet tucked away at the end of many of these pieces is a gently stated but powerful methodological moral for our times.

The essays are arranged in five sections. "Statistics and Social Sciences" begins with Pearson's relationships with the Cambridge economists, including the greatest: Marshall and Keynes. There are two chapters on Jevons and a very fine essay on Edgeworth, important enough in their day, but now almost unknown. After a bicentennial homage to Quetelet, we proceed to Galtonian notions. Stigler guides us through the traps of regression, with special reference to a bizarre series of tables published in 1933 by one Horace Secrist, who proved that American business was (necessarily, as shown by the mathematical theory of regression, and, in fact, as established by observation) regressing towards mediocrity. What seems like anecdote is, in fact, a veiled denunciation of the number-crunchers who employ vast software programs with no idea of the ideas they deploy, and no comprehension of the numbers that result.

As we progress through the book Stigler the detective becomes more and more in evidence. A bookseller's list piques his curiosity with a 1695 tract on The Art ofCuring Diseases by Mathematics, written by Sir Edward Eizat to denounce 'A.P.. This leads us to Edinburgh poet and physician Archibald Pitcairne (1652-1713), who opposed the unscientific medical practices of his day with a new theory of medicine based on mathematics. Any morals to draw here? This spat, by no means foolish in its details, is an example of what happens when mathematics tries to intrude into fields where there are already practitioners.

\section{Aventis Prizes for Science Books 2000}

The Elegant Universe by heretical theorist Brian Greene (Vintage, $\mathfrak{E 7 . 9 9 , ~ \$ 1 5 , ~ p b k ) ~ h a s ~ w o n ~ t h i s ~}$ year's Aventis Prizes General Prize — often called the scientific community's Booker Prize. The prizes were set up in 1988 by the Science Museum and COPUS, the Committee On the Public Understanding of Science, to encourage the writing, publishing and sale of popular science books for non-specialist readers. This year's general prize, worth $£ 10,000(\$ 15,000)$, attracted a record 117 entries. Other books on the shortlist are shown below. (See overleaf for coverage of the junior prize.)

The White Death: A History of Tuberculosis by Thomas Dormandy Hambledon/New York University Press, £25, \$29.95

\section{A Brief History of the Future: The}

In his section on naming, we are presented with Stigler's Law of Eponymy. The law states that (on the Principle of Humility) no law, theorem, principle or phenomenon is named after the person who discovered it. Its name is a joke: by self-reference, Stigler cannot have been the first to hit on Stigler's Law and, sure enough, he gives the credit to the sociologist of science Robert K. Merton. Humility triumphs, after all.

Various figures cross this section Gauss, Euler, Pearson - but "Who discovered Bayes's Theorem?" conveys the flavour. Richard Price published Bayes's most famous paper in 1765, four years after Bayes's death, but Stigler's Law says there must be a forgotten precursor. And yes, there is a mention of what sounds very much like Bayes's ideas in work published in 1749 by David Hartley, founder of associationist psychology. Hartley says of the Bayes-like result that it was communicated to him by an "ingenious friend". Who?

Stigler unearths a remarkable forgotten mathematician named Nicholas Saunderson. A good candidate, on data provided. But what would increase the credibility? In order to possess the requisite mathematics, including the binomial expansion, the friend would have to have read Abraham de Moivre, who set out matters clearly in a miscellany published in 1730. So who read de Moivre? Examine the list of subscribers to the first printing: Saunderson is there. From this and other reflections Stigler derives a list of suspects whom he will summon into the parlour his metaphor. After he has put all his data on the table, Stigler's 'Bayesian [ sic] calculation' gives odds of 3 to 1 on Saunderson. This is vintage Stigler.

Ian Hacking is in the Department of Philosophy, University of Toronto, 215 Huron Street, Toronto, Ontario M5S 1A1, Canada.
Origins of the Internet

by John Naughton

Weidenfeld \& Nicholson/Overlook, £18.99/\$27.95

Genome: The Autobiography of a Species in 23 Chapters

by Matt Ridley

Fourth Estate/HarperCollins, £9.99(pbk)/\$26 (hbk)

Time, Love, Memory: A Great Biologist and his Quest for the Origins of Behaviour

by Jonathan Weiner

Faber \& Faber/Knopf, £20/\$27.50

Children of Prometheus: The Accelerating Pace of Human Evolution by Christopher Wills

Allen Lane/Perseus, £20 (hbk)/\$15 (pbk) 